\title{
"Is There a Problem about Fictional Discourse"? J. Searle vs. R. Rorty
}

\section{Serious Discourse about Fictional Discourse. Searle's Text-centered Conception}

John Searle ends his famous article, The Logical Status of Fictional Discourse, published in New Literary History in 1975, with a rather unoptimistic statement:

that so far, there has been no general theory which explains the mechanism due to which pretended illocutions convey illocutionary intentions ${ }^{1}$.

If we take into account that even now, 38 years after publishing Searle's theses, we still discuss this old (ancient, in fact) problem of the status of sentences given in the text of a work of fiction, this final statement will sound even more pessimistic. Thus, here come some fundamental questions:

1 J. R. Searle, The Logical Status of Fictional Discourse, "New Literary History" 6 (1975), s. 332. In the present paper I use the terms: fiction and fictionality according to Searle's definition. However, analyzing the phenomenon of fiction, more terms should be taken in consideration: fictional, fictive, fictitious, as well as literariness. They should be distinguished in a very precise way. I try to do it by analyzing their usage domains in the article: M. Cyzman, Beyond Objectiveness: Non-dualism and Fiction, "Constructivist Foundations" 8/2 (2013). The special issue: Non-dualism: A Conceptual Revision, Alexander Riegler, Stefan Weber (eds.), pp. 174-175. 
1. Is it really necessary to do research on the logical status of fictional sentences/fictional text?

2. Under what kind of conditions (logical, ontological, epistemological) may this type of discourse be considered as sensible, useful and what kind of functions does it fulfill?

Thus, the aim of this paper is not to give an answer to the question of what fiction is (or what kind of semantics are characteristic for fictional discourse); I would prefer to consider some necessary foundations and presuppositions given in the deep structure of Searle's deliberations. John Searle had to assume some ontological and epistemological conditions in order to formulate his theses. They are consequences of the special thinking, typical - as I claim - for philosophy of language for which the ontologizing is treated as an obligation ${ }^{2}$. The ontologizing is the special procedure performed in the discourse in which the text perceived as an independent object - is placed in the center of semantic analyses.

However, at the very beginning of this paper, it is necessary to describe Searle's notion of fiction which seems to be still inspiriting for researchers working in the field of a linguistically orientated theory of fictional discourse.

John Searle's conception is founded on John L. Austin's doctrine of etiolating of languages. The formulation of this doctrine is the consequence of dividing the statements into two subsets: non-literal statements and the statements which are deviant, non-serious. For Austin, there are some types of speech acts touched by etiolating: poems, acting, literary fiction, declamation, jokes, muttering, repeating someone's remarks, uttering sentences while learning foreign languages, and quoting. He understands them as non-full acts and in order to describe their phenomenon introduces the term of parasitic speaking which is not particularly normal ${ }^{3}$. A literary work - an element of sets that are influenced by etiolating - ought to be shortly defined as a non-serious text with a fictional reference and fictional instances of sending and receiving. Although we cannot treat these theses as a foundation of a full theory of fiction, we should accept the important role of Austin's deliberations played in the

2 This notion - ontologizing - is used by me in the article Beyond Objectiveness: Non-dualism and Fiction, "Constructivist Foundations" 2013 , Vol. 8, No. 2, pp. 173-182.

3 J. L. Austin, How To Do Things With Words: the William James lectures delivered at Harvard University in 1955 / J. L. Austin; J. O. Urmson, M. Sbisa (eds.), Oxford 1986. On the problem of etiolating see also: W. Tomasik, Od „etiolacji” do "ideologii szczerości”. Teoria aktów mowy a literatura, „Pamiętnik Literacki” 1990, z. 3, p. 115-144; M. Cyzman, The Logical Status of Fictional Discourse' by John Searle - a still possible solution to an old problem?, "Logic and Logical Philosophy" (2011), Vol. 20, No. 4, pp. 317-326. 
contemporary philosophy of language. Thus, John Searle, Richard Ohmann, Mary L. Pratt, Barbara Smoczyńska (among others) developed Austin's point of view providing the means of expressing a special status of a literary work - understood as an act of speech of the representative type, but with a different reference to reality and a different function in the language universe.

John Searle doubts the possibility of distinguishing two fundamental notions: fiction and literature. They are not synonymous; that is why identifying fiction with literature is a mistake as not every literary work consists of fictional assertions - pseudo-assertions. Using Wittgenstein's term, Searle assumes that literature is a family of meanings, and its definition is based upon a present cultural situation. Continuing Austin's deliberations, Searle pays attention to the fact that fiction refers to the wider set of objects; a literary work is only one of them. His theses are connected rather with fiction, not with literature itself. Researching on fiction, Searle formulates (or: wants to formulate) the general theory of fiction. Thus, John Searle puts the emphasis on semantic and pragmatic conditions that assertions fulfil in a work of fiction. These assertions are of ambivalent nature: understood as standard illocutionary acts, fictional assertions have the same meanings as assertions used in non-fictional acts of speech (another solution is unacceptable - if fictional discourse controls different meanings of words, the work of fiction will not be comprehensible for the reader), but - on the other hand -fictional assertions lack the author's commitment to truthfulness. They expresses the meaning understandable for the reader but without semantic conditions typical of a normal act of speech. This observation leads Searle to the conclusion that the author of a work of fiction pretends to perform a series of standard illocutionary acts but without the intention of misleading anyone (as a result, it is impossible to treat assertion of this type analogically as a lie). There are two types of conventions describing semantic commitment to the extra-linguistic reality: horizontal conventions and vertical conventions. The extra-linguistic horizontal conventions - characteristic for the fiction - break the vertical rules which establish connections between words from the text and the object in the reality. However, it should be noted that these conventions are abstractive as, according to Searle's deliberation, it is impossible to point them out in the text. It is not very clear how to distinguish between them by considering the type of the sentences in the text. Fictionality is not a feature of the text that would allow it to be considered as fictional. Answering the question, what makes the discourse fictional, Searle uses the term of the illocutionary attitude of the author toward the discourse. That is the author who decides whether his text is fictional or non-fictional. He/she does not perform at the same time a special illocutionary act of telling a story or writing 
a novel as the fictional discourse expresses the same, standard meanings of words 4 .

One of the most problematic assumptions given in Searle's text is the concept of reference. According to Searle's axioms of reference, especially the axiom of existence, the fictional discourse standard reference does not function. The act of reference is pretended and in this way the author of a work of fiction pretends the object exists. However, if the author of the work of fiction makes general judgements about reality, he performs a fortunate illocutionary act in this manner. In Searle's opinion, in the fictional discourse, there are two types of acts of reference: genuine acts of reference, which is followed by genuine illocutionary acts, and pretended acts of reference connected with fictional objects understood as the author's creation, the fruit of his imagination. It leads Searle to the conclusion that a work of fiction, in general, does not only consist of fictional discourse; as a result we reach for the conception of heterogenic text and - as its simple consequence - ontological duality. Fictional discourse consists of both genuine and pretended illocutionary acts, and the world presented in a literary work is divided into two subsets: real objects and fictional, non-existent objects.

John Searle does not provide an answer to the question whether demarcation between pretended and non-pretended illocutionary acts, analogously: between pretended and non-pretended acts of reference, is possible. The criterion of distinguishing one from another is not clearly defined by Searle. Actually, this problem does not exist in his deliberations, which seems to be strange, pointing to the fact that pretended illocutions cause perlocutionary effects in the extra-literary reality ${ }^{5}$. Searle does not focus his attention on the fact that pretended illocution from an author's s point of view does not have to be automatically understood by the reader as pretended (and the other way round). Thus, Searle's notion of fiction is based on the vague demarcation between pretended and non-pretended illocution ${ }^{6}$. Moreover, the discourse itself does not contain any indicators, which would allow us to distinguish the status of the ontological object of reference. The examples given by Searle are problematic and they do not solve the main problem - using the authentic personal proper name functioning in extra-literary reality does not

4 R. Ohmann presents a different point of view, see: R. Ohmann, Speech Acts and the Definition of Literature, "Philosophy and Rhetoric" 4 (1971), 1, pp. 1-19; Literature as Act. In: Approaches to Poetics, ed. S. Chatman, New York-London 1973, pp. 81-107. See also my analyses in: M. Cyzman, The Logical Status of Fictional Discourse' by John Searle - a still possible solution to an old problem?, pp. 317-326.

5 W. Tomasik, Od "etiolacji” do „ideologii szczerości”. Teoria aktów mowy a literatura, pp. $115-144$.

${ }^{6}$ See more analyses in: M. Cyzman, The Logical Status of Fictional Discourse' by John Searle - a still possible solution to an old problem?, pp. 317-326. 
decide the authenticity of the object it refers to. It also provokes more problematic questions: for example - how to measure this authenticity, what difference does this recognition of the potential authenticity make for our understanding of fictional text? Searle does not take into consideration the reader's point of view - the pretended reference or authentic information from one reader's point of view would not necessary have this character for the second, the third, and the fourth reader, or even for the author. Where is the adjudicating authority? It should be assumed somehow in Searle's conception in order to defend the sensibility of the thesis that there are two different groups of illocutionary acts in a work of fiction. If it is not possible to point out this kind of authority, the research on the differences between the logical status of fictional sentences seems to be useless.

John Searle puts an emphasis on the fact that determining one certain and empirically adequate definition of a literary work is impossible due to the obvious historical changeability of the term of a literary work. However, as I have mentioned above, the author of The Logical Status of Fictional Discourse does not link his thesis with the reader's point of view, excluding the receiver's consciousness from his deliberations. If the notion of a literary work, as well as the notion of fiction, is adjusted to a present cultural situation - as Searle rightly suggests - searching essential features of fictional discourse seems to be pointless. There are rather culturally sanctioned indicators of fiction functioning in each interpretive community (the term taken from S. Fish's conception ${ }^{7}$ ). The philosopher bases his understanding of fictionality on the assumption that there are not any features of the text which would allow us to consider it as fictional. However, in the same text, Searle puts the emphasis on the fact that in a work of fiction we can also find genuine illocutionary acts and genuine acts of reference. This contradiction leads us to the conclusion that Searle still locates the meaning of fiction primarily in the objective text, not in an extra-fictional order as his initial pragmatic perspective of research could suggest. Thus, I claim that John Searle's deliberations (still!) are representative of the text-centred, essentialist thinking in a reflection on fiction.

7 See for example: S. Fish, What Makes an Interpretation Acceptable? In Is There a Text in This Class? The Authority of Interpretive Communities, Cambridge, Massachusetts, London, England: Harvard University Press, 1980, p. 338-355. 


\section{Serious Discourse about Non-Serious Problem? Rorty's Story about Searle's Conception}

Richard Rorty also focuses his attention on the basic assumptions of Searle's thesis, considering them in the terms of language games. Thus, according to his deliberations, there are two distinct language games, fictional discourse and real world talk. Considering the sensibility of Searle's axiom of existence, Rorty formulates the conclusion that it causes ambiguity and triviality. The existence should be understood as ordinary spatio-temporal existence, analogously to Russel's thesis, but also as ability to be referred to a language game parasitic on the real world ${ }^{8}$. Rorty suggests that there is no real difference between the axiom of existence and the axiom of identity as the ability to refer to an object in a work of fiction is nothing but the ability to keep up a coherent conversation about it. Thus, Richard Rorty's central thesis is that according to Searle's considerations, it is impossible to formulate nontrivial sense to his axiom of existence. Searle did not solve the problem of relating words to the world and did not present a coherent theory of fictional discourse. The philosopher commits himself to the point that there are conventions which permit us to talk as if we believed that something existed even when we did not. Rorty finds this remark sensible but at the same time too weak to be the base of the theory Searle wants to formulate.

However, Rorty goes far further in his commentary on, not only, Searle, but also Russels's, Donellan's and Meinong's theses. His central conclusion is that the differences between traditionally distinguished assertions (genuine and pretended in Searle's terminology) are not revealed by semantics. This phrase implies that the philosophy of language concentrated on semantic problems is completely useless in telling us about how words relate to the world. Semantic research on discourse in Searle's style should be removed and replaced by a sociological study of the way in which people would justify each assertion ${ }^{9}$. Analogously, both: the notion of reference and the notion of truth understood in a classical way in correspondence with reality, are completely pointless. Rorty claims that all we need is the commonsensical notion of "talking about," where the criterion what a statement is "about" is just whatever its utterer "has in mind"- that is, whatever he thinks. He wishes to discard the notion of reference and the theory of reference. The question that arises here is why the phenomenon of analytic philosophy of language concentrating on the notion of fiction exists and why it is necessary to replace normal,

8 R. Rorty, Is There a Problem about Fictional Discourse? In Consequences of Pragmatism (Essays: 1972-1980), University of Minnesota Press, Minneapolis 1994, p. 11.

9 Ibidem, p. 128. 
epistemological statements with semantic expressions. For Rorty, this is the consequence of the still functioning assumption that there should be a very strong relation between epistemology and semantics. Semantics itself has not been disjoined from epistemology. Philosophers want guarantees out of semantics that we will not lose touch with the world. In order to do that it is necessary to preserve the notion of reference and the notion of fiction. Meanwhile, not one of the theories of this type has answered the fundamental question of whether having knowledge differs from making poems or telling stories. The commonsensical notion of talking about seems to be unsatisfying or not taken seriously which is why notions such as reference or fiction are still alive in philosophical discourses.

Commenting on the expression of the captivating picture which is formulated in Wittgenstein's Tractatus, Rorty pays attention to the fact that his language game approach permits the idea that if a sentence makes sense, it is dependent upon whether another sentence is true. Analogously, in the case of fictional discourse this rule functions. By dropping "the depicted picture idea", we reach for the conception in which philosophical problems about fiction do not arise or - more precisely - there is no need to create such a conception as there is no need to ask, for example, how scientific theories may be philosophically, logically distinguished from poems and so on. Commenting also on Heidegger's theory in which it is assumed that fear against losing essential togetherness of Being and Apprehension was Plato's inheritance from Parmenides, Rorty claims that all history of epistemology and semantics grounds predicative discourse on a nonconventional relation to reality. As a result, predicative discourse has been divided into two subsets: the first corresponds to the truth, and the second one - called the Way of Opinion - lacking correspondence of this type. Accordingly, we can refer to two types of paradigm to each subset: the knowledge is a paradigm for the Way of Truth and the poetry is a paradigm for the Way of Opinion. Following Heideger's deliberartions, Rorty claims that a distinction between knowledge and opinion or science and poetry would not be possible without Plato's assumption of analogue between judgment and visual perception. This is the consequence of the model of Knowledge in which the truth of a proposition is perceived as referring to something occurring before our eyes (this is epistemology-of-vision).

The most typical discourse in modern western philosophy has its roots in the Parmenidean, Platonic, and Russellian word-world relationships. It refers to the classical conception of truth, which is called firstclass true in Rorty's analyses, and - in contrast - to a different type of word-world relationship, like parasitic act of speech, thus, as Rorty claims, the second-rate sort of truth possessed. Accordingly, with each type of truth, we should associate responsible and irresponsible discourse, 
serious and non-serious in Searle's terms, which results in a strict distinction between science and poetry. However, these deliberations do not lead Rorty to the conclusion that the liberation from Parmenidean tradition is necessary. In fact, the philosopher does not agree with Derrida in claiming that there is nothing outside the text and questioning the notion of reference ${ }^{10}$. Although there are a thousand poets, like Borges, Nabokov, and Mallarme, constructing the worlds without subjectand-object dichotomy, word-and-meaning, language-and-world distinctions, the total negation of Parmenidian tradition would be a great mistake as in a culture without any contradictions between science and poetry, this type of writing would be completely senseless. They use the Parmenidean tradition as a dialectical foil, which makes their existence possible. That is why Rorty ends his article with the significant statement: The scientific culture could survive a loss of faith in this tradition, but the literary culture might not ${ }^{11}$. According to Rorty's deliberations, the discourse about fiction should transform itself into criticism and in this way, it may become the literary practice. Thus, both of them, literary practice and literary theory, are aimed at the creation of new terminologies, new hypotheses and new descriptions of the world.

\section{Searle's (Non-Serious) Fears?}

Richard Rorty assumes that a central set of Parmenidean presuppositions is common to four conceptions about fiction and reality: (1) the standard Russellian theory; (2) John Searle's notion of pretended assertion, (3) a physicalist view of reference to the inexistent objects formulated by Keith Donnellan; (4) Meinongianism modified by Terence Parsons in order to define Alexius Meinong's notion of intentional objects. Although the last three of these theories are formulated against Russell's view, they represent the same type of foundations and presuppositions, Parmenidean, as Rorty claims. Let me consider some consequences of these views, assuming that Searle's conception is only an example of the special essentialist thinking about relation between fiction and reality, representative for the text-centered theory of fictional discourse.

The desire to preserve the textual objectivity and the notion of the non-changeable nature of the object, has its roots - as Rorty rightly suggests - in the fear that without locating senses in the text we reach for the conception of subjectivity and there would be nothing sensible to say about the text. Analogously, all the text-centered methodological strat-

10 Let me mention that this is only Rorty's interpretation, in fact, Derrida's theory seems to be more complicated.

11 R. Rorty, Is There a Problem about Fictional Discourse?, p. 137. 
egies are aimed at separating literature/fictional discourse form other kinds of discourse (serious in Searle's terminology) in order to give to criticism an objective basis and objective tools for its procedures. If there were no disputes over fiction/strict distinction between fiction and reality, the humanistic research could be perceived by many as unnecessary and valueless. However, the interesting thing is that, in fact, the discourse about fiction becomes rather the example of methodological strategy, showing its possibilities and limitations but never the nature of fiction itself!

Removing the notion of fiction as an essentialist feature of a text from ontologically and linguistically orientated research is characteristic of contemporary thinking about fiction. This cultural, pragmatic and ethical turn is aimed at the new type of discourse in which research on semantics of the text is replaced by research on the model of the world and its descriptions functioning in each interpretative community. In a conception based on radical constructivism ${ }^{12}$, it is assumed that both: reality created in fictional discourse and reality given in different types of discourse have a constructive character ${ }^{13}$. Fiction is also perceived as a phenomenon which does not create other kinds of ontological worlds; fiction and non-fiction are understood as factual worlds, although, in addition, the art recreates and renews the description of the world functioning in every culture ${ }^{14}$. Considering these theories as the conceptions having their roots in non-essentialist and non-ontological way of thinking, we should take into account that, anyway, each of them makes the object of analyses dependent on its own language of description. They are also the manifestation of a methodological strategy (if a kind of methodology is assumed) and the operational force of its tools and notions. The distinction between fiction and reality functions as an axiom providing the common background for the theory itself and making it logically necessary. This main dichotomy, fiction versus reality, founds these conceptions and seems to be the result of (still!) dualizing perspective from which the recent research on fiction has been done. Richard Rorty questioning the necessity of research on semantic indicators of fiction, does not negate the Parmenidean roots of the theories he describes. What is interesting, even his conception is based upon the set of foundations

12 Ernst von Glasersfeld invented the term of radical constructivism and formulated a definition of this strategy of thinking; although there were similar tendencies before Glasersfeld's main works. E. von Glasersfeld, An introduction to radical constructivism. In The Invented Reality: How Do We Know What We Believe We Know? (Contributions to Constructivism), P. Watzlawick, W. W. Norton, C. Norton (eds.), New York, pp. 17-40.

13 S. Schmidt, Fictionality in literary and non-literary discourse, "Poetics" 9 (5-6), pp. 525-546.

14 N. Goodman, Ways of worldmaking, Hackett Publishing Company, Indianapolis 1978. 
and presuppositions taken from this classical idea. As Anna Łebkowska rightly claims, fiction, especially so glorified by Rorty's ironic fiction, functions only in the light of Parmenidean theories. They fulfill their negative, but at the same time necessary, context. ${ }^{15}$

My central thesis assumes that there is no serious problem about fictional discourse, there is rather a problem with our attitude to the discourse about fictional discourse. There is no fictionality in itself. Fictionality is an exterior description associated with a text, not an interior feature which can never be perceived. It is a description which content is derived from the interpretive community in which fiction (what is perceived as fictional) fulfills a particular function. Traditionally, in all philosophical and literary research based upon classical dualizing epistemology ${ }^{16}$, fictionality has been perceived as an essentialist feature (of the statement or an object) which makes some texts and some objects different from reality and modify the global sense or global resonance of the text. The assumption that fiction does not appear in any kind of text seems to be a natural consequence of the thesis that the meaning of the text has no existence outside its perception performed by the receiver, especially the reader of fictional discourse. If the distinction between fiction/literature and reality is founded by presuppositions or the picture of the world existing in every interpretative community, the discourse about fiction communicates rather the general knowledge of this community, which is changeable and occasional, not the general essentialist nature of fiction itself. Stanley Fish and other representatives of reader-response-criticism have already removed the text from the center of critical attention, correspondingly classical research on fiction has been replaced with research focusing on what readers assume as fictional and how these assumptions modify the cognitive attitude toward the text. Therefore, the distinction between fiction and reality, Searle's main problem, is what you - as a reader - assume as a distinction.

In Searle's conception, the discourse about fictional discourse lays in the level above the fictional discourse. The researcher still wants to formulate a theory based on the recognition of some objective and provable features of the text. However, Searle does not focus his attention on the fact that there is no indirect insight into the text. According to Mit-

15 A. Łebkowska, Między teoriami a fikcja literacka, Kraków: Universitas, 2001, pp. 112-113.

16 The dualizing philosophy is based on dichotomies: word and object, object and description, subject and object, see: J. Mitterer, Tamta strona filozofii. Przeciwko dualistycznej zasadzie poznania, trans. M. Łukasiewicz, Warszawa: Oficyna Naukowa, 1996. Originally published as: J. Mitterer, Das Jenseits der Philosophie. Wider das dualistische Erkenntnisprinzip, Passagen, Vienna 1992. 
terer's deliberations, the discourse about fiction starts from the text and changes it. As Mitterer claims, text and interpretation, as well as the object and description, form a unity. The object is nothing but a description so far which is lead further by a description from now on. The description of the object creates a new object of the further description. The metalevel is excluded from the discourse ${ }^{17}$. Philosophical texts, essays in literary criticism or literary theories have the same status as texts from which they are derived. As a result we reach for the idea of a great dynamic and everlasting circulation of discourses/stories, always in action. However, here comes the question, what difference does it make in comparison with a traditional view on the problem of fiction? I would list three of them, these I consider the most important. The first change is connected with the way by which any stalemate situations may be solved. Rorty and Mitterer postulate the discussions, negotiations instead of truth claiming which always results in the necessity of using a power. The second refers to the new direction of thinking in which abstractive discourse aimed at truth is replaced by pragmatic discourse aimed at change. And the third one assumes that the function of fiction - in a particular interpretive community as well as for the individual - is more important than any formulations of global theories. It changes the limits of our questions. How does fiction influence our life? How does it change ourselves? How does it appear in our discourses? The ontological questions can never be asked in such a model of thinking.

Will these considerations lead us to the conclusion that the discourse about fictionality (philosophically or literary orientated) is completely unnecessary, senseless and unimportant?

From my Mittererian perspective, the essentialist, text-centered discourse and pragmatic discourse about fiction are similar to each other in the sense that even Searles' theory (as well as every essentialist textcentered theory) is only a discursive construction of a notion of fiction and fictionality. It refers to the assumptions covering the text perceived as fictional, to the philosopher's interpretation of fictionality, not to the text itself as it is always - as Mitterer claims - dumb and silent ${ }^{18}$. From this perspective, the essentialist discourse about the fictional text is its discursive continuation, the only difference lays in the particular discursive techniques used by the author. In the situation of conflicts he/she pays attention to the text itself and activates its authority which is supposed to solve interpretive problems. However, it is also the specific con-

17 J. Mitterer, On Interpretation, “Constructivist Foundations" 8/2 (2013). The special issue: Non-dualism: A Conceptual Revision, Alexander Riegler, Stefan Weber (eds.), pp. 143-147. We can treat the philosopher's deliberations also as the foundation of the thinking about fiction.

18 Ibidem, p. 144. 
struction of the notion of the text as no one has indirect insight into it. Therefore: will the discourse about fictional discourse still have a reason to exist? Will we lose the real, serious, scientific value of research on fictionality? Yes and no. Yes as from a constructivistic, pragmatic and nondualizing perspective it has never had such value. Theory is nothing but a description or set of descriptions. No - as in the global circulation of discourses which build our culture fictional stories are as important as nonfictional stories. Moreover as long as there will be a necessity to construct literature, there will be the need to construct the stories about them (from them, according to Mitterer's new direction of thinking). And as long as there will be the institutions interested in such a discourse, we should not be afraid of losing the sensibility of our work. It will be as serious as a particular institution is able to take it seriously ${ }^{19}$.

Furthermore, which discourse is more sensible - this is the matter of preference, not reference ${ }^{20}$.

\section{Bibliography}

Austin J. (1986), How To Do Things With Words: the William James lectures delivered at Harvard University in 1955 / J. L. Austin; ed. by J. O. Urmson and M. Sbisa, Oxford.

Cyzman M., Beyond Objectiveness: Non-dualism and Fiction, "Constructivist Foundations" 8/2 (2013). The special issue: Non-dualism: A Conceptual Revision, Editors: Alexander Riegler \& Stefan Weber, p. 174-175.

Cyzman M., The Logical Status of Fictional Discourse' by John Searle - a still possible solution to an old problem?, "Logic and Logical Philosophy" 2011, t. 20, nr 4, s. 317-326.

Fish S., What Makes an Interpretation Acceptable? in: Is There a Text in This Class? The Authority of Interpretive Communities, Harvard University Press, Cambridge, Massachusetts, London, England 1980, p. 338-355.

Glasersfeld E. von, An introduction to radical constructivism, w: The Invented Reality: How Do We Know What We Believe We Know? (Contributions to Constructivism), ed. P. Watzlawick, W. W. Norton and Co, Norton, New York, s. 17-40.

Goodman N., Ways of worldmaking, Hackett Publishing Company, Indianapolis 1978.

Łebkowska A., Między teoriami a fikcja literacka, Universitas, Kraków 2001, p. 112-113.

19 See also R. Rorty's point of view: R. Rorty, Text and Lumps. In R. Rorty, Objectivity, Relativism, and Truth. Philosophical Papers. Vol. 1, Cambridge University Press, 1995, p. 78-92.

20 J. Mitterer, On Interpretation, “Constructivist Foundations” 8/2 (2013), p. 147. 
Mitterer J., On Interpretation, "Constructivist Foundations" 8/2 (2013). The special issue: Non-dualism: A Conceptual Revision, Editors: Alexander Riegler \& Stefan Weber, p. 143-147.

Mitterer J., Tamta strona filozofii. Przeciwko dualistycznej zasadzie poznania, trans. M. Łukasiewicz, Oficyna Naukowa, Warszawa 1996. Originally published as: J. Mitterer, Das Jenseits der Philosophie. Wider das dualistische Erkenntnisprinzip, Passagen, Vienna 1992.

Ohmann R. (1971), Speech Acts and the Definition of Literature, "Philosophy and Rhetoric" 4, nr 1, s. 1-19.

Ohmann R. (1973), Literature as Act, in: Approaches to Poetics, ed. S. Chatman, New York-London, s. 81-107.

Rorty R., Text and Lumps, in: R. Rorty, Objectivity, Relativism, and Truth. Philosophical Papers. Vol. 1, Cambridge University Press, 1995, p. 78-92.

Rorty R., Is There a Problem about Fictional Discourse? in: Consequences of Pragmatism (Essays: 1972-1980), University of Minnesota Press, Minneapolis 1994, p. 110-138.

Schmidt S., Fictionality in literary and non-literary discourse, "Poetics" 9 (5-6), p. $525-546$.

Searle J. R. (1975), The Logical Status of Fictional Discourse, „New Literary History" 6, p. 319-332.

Tomasik W. (1990), Od „etiolacji” do „ideologii szczerości”. Teoria aktów mowy a literatura, „Pamiętnik Literacki” z. 3, s. 115-144.

\section{Summary}

John Searle's and R. Rorty's deliberations represent two different view on a problem of fictional discourse. Searle still locates the meaning of fiction primarily in the objective text, not in an extra-fictional order as his initial pragmatic perspective of research could suggest. Therefore, his conception is still representative of the text-centred, essentialist thinking in a reflection on fiction. R. Rorty formulates the thesis that Searle did not solve the problem of relating words to the world and did not present a coherent theory of fictional discourse. According to Rorty's deliberations, the discourse about fiction should transform itself into criticism and this way, it may become the literary practice.

Removing the notion of fiction as an essentialist feature of a text from ontologically and linguistically orientated research is characteristic of contemporary thinking about fiction. This cultural, pragmatic and ethical turn is aimed at the new type of discourse in which researching on semantics of the text is replaced by the research on the model of the world and its descriptions functioning in each interpretative community.

In the present paper I try to answer some important questions founded on the comparison of these two different conceptions, for example: is the discourse about fictionality (philosophically or literary orientated) useful and sensible and what kind of functions does it fulfill. I claim, following Josef Mitterer's non-dualiznig philosophy and Rorty's considerations, that as long as there will 
be the institutions interested in such a discourse, there will be reasons to construct them and there is no need to be afraid of losing the sensibility of our work.

\section{Keywords}

fiction, pretended illocutions, language games, description so far/from now on, interpretive community, institution, essentialist text-centered theory, pragmatic conception, theories vs. telling stories 